\title{
Abordagem multivariada do fluxo de tecidos em pastos de Brachiaria brizantha
}

\author{
Caio Vinicio Vargas de Oliveira', Rodrigo Amorim Barbosa², Raísa Turcato de Oliveira', Patrick Bezerra \\ Fernandes ${ }^{3}$
}

${ }^{1}$ Instituto Federal de Educação, Ciência e Tecnologia Goiano - Campus Rio Verde, GO. ${ }^{2}$ Empresa Brasileira de Pesquisa Agropecuária - Gado de Corte, Campo Grande, MS. ${ }^{3}$ Universidade Federal do Mato Grosso do Sul - UFMS, MS. E-mail: zoo.patrick@hotmail.com

\section{Resumo}

A hipótese testada foi que pastos de clima tropical da mesma espécie, porém com hábitos de crescimento distintos, apresentariam oscilações na plasticidade fenotípica ao longo do ano. Assim, o presente trabalho visa avaliar as características morfológicas e estruturais de cultivares de Brachiaria brizantha em sistema de pastejo em lotação intermitente. O experimento foi conduzido Empresa Brasileira de Pesquisa Agropecuária - Centro Nacional de Pesquisa em Gado de Corte. O delineamento experimental utilizado foi de blocos casualizados com três tratamentos e três repetições, totalizando nove unidades experimentais (piquetes). Cada piquete foi constituído de uma área de 1,5 hectares igualmente subdividida em seis subunidades (réplicas) em método de pastejo lotação intermitente. Os tratamentos foram constituídos por gramíneas da mesma espécie (Brachiaria brizantha) compostas pela Brachiaria brizantha cv. Xaraés, BRS Paiaguás e o ecótipo B4. Utilizou-se os dados de morfogênese e estrutura para estimar as primeira e segunda variáveis canônicas, bem como os coeficientes canônicos padronizados. Os coeficientes canônicos padronizados da primeira variável canônica mostraram que filocrono e duração de vida de folha são as variáveis que mais interferem sobre a primeira variável canônica. A primeira variável canônica explica $95 \%$ da variação no fluxo de tecidos, além disso, é possível observar uma distribuição diferenciada no fluxo de tecidos entre os pastos estudados. Diante disso, em manejos baseados em lotação intermitente recomenda-se que para a diversificação de espécies em ambientes pastoris, a cultivar Xaraés seja utilizada como principal recurso forrageiro no período das águas e a BRS Paiaguás seja utilizada de forma estratégica no período seco. A plasticidade fenotípica dos pastos $B$. brizantha pode ser elucidados pela duração de vida de folha e filocrono.

Palavras - chave: morfogênese; pastejo; plasticidade fenotípica.

\section{Multivariate approach of tissue flow in pastures of Brachiaria brizantha}

\begin{abstract}
The hypothesis tested was that pastures of tropical climate of the same species, but with distinct growth habits, would show oscillations in phenotypic plasticity throughout the year. Thus, the present work aims to evaluate the morphological and structural characteristics of cultivars of Brachiaria brizantha in grazing system in intermittent stocking. The experiment was conducted by the Empresa Brasileira de Pesquisa Agropecuária - Centro Nacional de Pesquisa em Gado de Corte. The experimental design was a randomized block with three treatments and three replicates, totaling nine experimental units (pickets). Each picket consisted of an area of 1,5 hectare also subdivided into six subunits (replicas) in a rotational grazing method. The treatments were composed by grasses of the same species (Brachiaria brizantha) composed by Brachiaria brizantha cv. Xaraés, BRS Paiaguás and ecotype B4. Morphogenesis and structure data were used to estimate the first and second canonical variables, as well as the standardized canonical coefficients. The canonical standardized coefficients of the first canonical variable showed that phyllochron and leaf life span are the variables that most interfere with the first canonical variable. The first canonical variable explains $95 \%$ of the variation in the tissue flow, in addition, it is possible to observe a distribution in the flow of tissues between the studied pastures. Therefore, in management based on intermittent stocking it is recommended that for the diversification of species in pastoral environments, cultivar Xaraés be used as
\end{abstract}


the main forage resource in the period of waters and BRS Paiaguás be used strategically in the dry period. The phenotypic plasticity of $B$. brizantha grasses can be elucidated by leaf and phyllochron life.

Keywords: morphogenesis; grazing; phenotypic plasticity.

\section{Introdução}

Os componentes estruturais do dossel forrageiro sofrem forte influência das características morfogênicas, que são geneticamente pré-determinadas (LEMAIRE et al., 2009; MAZZANTI e LEMAIRE 1994), no entanto dependendo do manejo imposto aliado aos fatores abióticos, as características morfoestruturais do dossel forrageiro podem ser modificadas (BARBOSA et al., 2011; DIFANTE et al., 2011).

Assim, para caracterizar as diferenças que possam haver entre as espécies forrageiras, é necessário verificar em nível de perfilho individual as possíveis oscilações no fluxo de tecidos, e traduzir de forma correta o que cada variável relacionada à morfogênese revela sobre os impactos da interação genótipo e ambiente (LEMAIRE et al., 2009).

Diante disso a hipótese testada foi que pastos de clima tropical da mesma espécie, porém com hábitos de crescimento distintos (EUCLIDES et al., 2008; LARA; PEDREIRA, 2011), apresentariam oscilações na plasticidade fenotípica ao longo do ano. Assim, o presente trabalho visa avaliar as características morfológicas e estruturais de cultivares de Brachiaria brizantha em sistema de pastejo em lotação intermitente.

\section{Material e Métodos}

O experimento foi conduzido Empresa Brasileira de Pesquisa Agropecuária - Centro Nacional de Pesquisa em Gado de Corte (EMBRAPA - CNPGC, situada em Campo Grande MS, Lat. 2027' S, Long. 5437' W e Alt. 530m), as avaliações iniciaram em novembro de 2015, e finalizado em setembro de 2016. O clima da região, de acordo com a classificação de Köppen, é do tipo tropical chuvoso de savana, subtipo Aw, caracterizado pela ocorrência bem definida do período seco durante os meses mais frios do ano e período chuvoso durante os meses de verão (Figura 1).

Figura 1. Temperaturas média, mínima e máxima, precipitação mensal de setembro de 2015 a outubro de 2016.

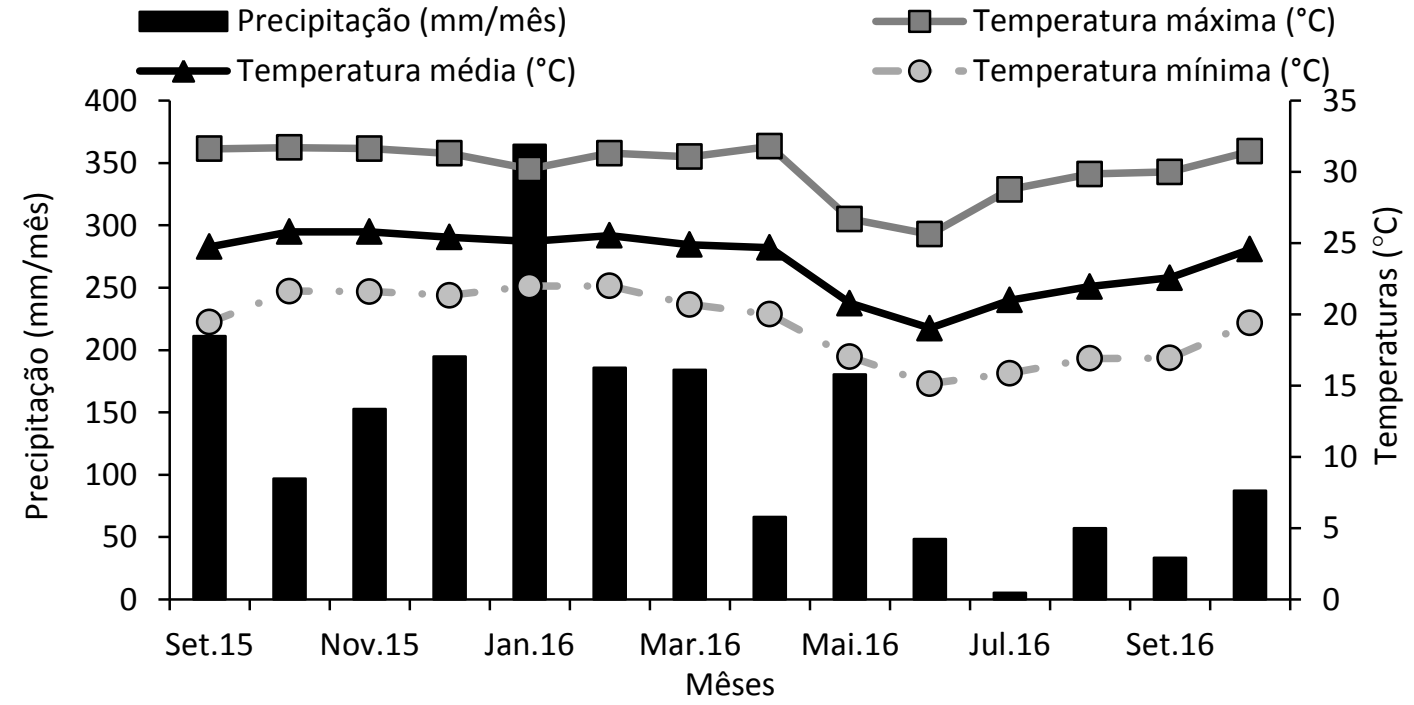

Para a realização do experimento, foram retiradas amostras de solo $(0-10,0-20$ e 0 - 40 $\mathrm{cm})$ para análise da fertilidade. $O$ solo da área experimental é classificado como Latossolo Vermelho Distrófico, caracterizado por textura argilosa, pH ácido, baixa saturação por bases e alta concentração de alumínio. Assim, a partir de 2010 realizou-se o preparo convencional do solo com correção com calcário dolomítico com o objetivo de elevar a saturação por bases a $50 \%$. 
Foram aplicados em cobertura, $40 \mathrm{~kg} \mathrm{ha}^{-1}$ de $\mathrm{P}_{2} \mathrm{O}_{5}$ e de $\mathrm{K}_{2} \mathrm{O}$, elevar o teor de fósforo para $4-8 \mathrm{mg}$ $\mathrm{dm}-3$ ( $\mathrm{P}-$ Mehlich1) e o teor de potássio para 60 $-80 \mathrm{mg} \mathrm{dm}^{-3}$ e $50 \mathrm{~kg} \mathrm{ha}^{-1}$ de FTE-BR12. Foram também aplicados $150 \mathrm{~kg} \mathrm{ha}^{-1}$ de $\mathrm{N}$ na forma de ureia, divididos em três parcelas nos meses de novembro, dezembro e fevereiro.

O manejo do pastejo utilizado foi sob lotação intermitente com cinco dias de pastejo e 25 dias de descanso, na época das águas (primavera e verão), e sete dias de pastejo e 35 dias de descanso na época das secas (outono e inverno). O delineamento experimental utilizado foi de blocos casualizados com três tratamentos e três repetições, totalizando nove unidades experimentais (piquetes). Cada piquete foi constituído de uma área de 1,5 hectares (ha) igualmente subdividida em seis subunidades (réplicas) em método foi 0 de lotação intermitente. Os tratamentos foram constituídos por gramíneas da mesma espécie (Brachiaria brizantha) compostas pela Brachiaria brizantha cv. Xaraés, BRS Paiaguás e o ecótipo B4.

Foram utilizados novilhos da raça Angus para a desfolhação dos pastos durante o período de ocupação os quais apresentaram peso médio inicial de $180 \mathrm{~kg}$ e foram pesados a cada 30 dias para estimar a densidade de lotação a cada ciclo de pastejo.

Para a estimativa da altura em prépastejo e de cada dia de ocupação foram registrados 30 pontos aleatórios em um subpiquete de cada módulo. Esta informação correspondeu a altura médias, em centímetros, em torno da régua. A densidade populacional de perfilhos (DPP $\mathrm{m}^{-2}$ ) foi estimada com o auxílio de três armações de $1 \mathrm{~m}^{2}$, alocadas aleatoriamente dentro de cada subpiquete, sempre em ocasião de pré-pastejo de cada ciclo. Foi registrado o número de perfilhos contidos dentro de cada armação que, posteriormente, integraram a média para cada tratamento.

Para realizar as estimativas de índice de área foliar (IAF) foram colhidas 300 lâminas foliares verdes, sendo 100 de cada gramínea para a integração da área das lâminas foliares (AF $\mathrm{cm}^{2}$ ). Assim foi possível obter IAF dada pela seguinte formula: $I A F=(A F \times D P P) /$ área do solo (adaptado de GASTAL; LEMAIRE, 2015).

Para realizar as avaliações relacionadas ao fluxo de tecidos, foi realizada a identificação dos perfilhos por meio de anéis plásticos coloridos para facilitar a localização dos mesmos utilizando a técnica de perfilhos marcados (HODGSON, 1966). Para tanto, foram identificados 45 perfilhos por tratamento, 15 por repetição, distribuídos em três réguas ( 5 perfilhos por régua). Cada régua foi alocada aleatoriamente no subpiquete, e os perfilhos alocados a cada $1 \mathrm{~m}$ de distância. Para cada período de avaliação era remarcado uma nova população de perfilhos.

No perfilho foi mensurado o comprimento do pseudocolmo (medido do solo até a última lígula completamente expandida), da lâmina foliar (medido a partir da lígula expandida até extremidade da lâmina) e da folha em alongamento (lígula da folha mais jovem completamente expandida até extremidade da lâmina em expansão) e o número de folhas vivas (NFV, folhas perfilho ${ }^{-1}$ ), a média do número de folhas em expansão e expandidas por perfilho durante o período de avaliação, excluindo-se as folhas que tivessem mais de $50 \%$ do seu comprimento em senescência, quando então era considerada morta.

Assim foi possível realizar os seguintes cálculos: taxa de aparecimento de folhas (TaPF, folhas perfilho ${ }^{-1} \mathrm{dia}^{-1}$ ); taxa de alongamento de folhas (TalF, cm de lâmina foliar perfilho ${ }^{-1} \mathrm{dia}^{-1}$ ); a taxa de alongamento de colmos (TalC, cm perfilho $^{-1}$ dia $^{-1}$ ); o filocrono (Filo. dias folha perfilho ${ }^{-1}$ ). A duração de vida das folhas (DVF, dias), sendo estimada pela equação: $D V F=N F V x$ Filo (CHAPMAN; LEMAIRE, 1996).

Utilizou-se os dados de morfogênese e estrutura para estimar as primeira e segunda variáveis canônicas, bem como os coeficientes canônicos padronizados. Utilizou-se a função Candisc, do software $R$ versão 3.5.0 para esta estimação.

\section{Resultados e Discussão}

Os coeficientes canônicos padronizados da primeira variável canônica (Can1), mostraram que Filo e DVF são as variáveis que mais interferem sobre a primeira variável canônica, de forma positiva e negativa. Isto indica que estas são as variáveis que mais interferem na diferenciação das características de morfogênese dos pastos avaliados. 
Tabela 1. Coeficientes canônicos padronizados da primeira e segunda variável canônica dos pastos de Brachiaria brizantha.

\begin{tabular}{ccc}
\hline Variável & Can1 & Can2 \\
\hline TaPF & 0,954 & 0,658 \\
Filo & 1,74 & $-0,697$ \\
TalF & $-1,21$ & $-1,20$ \\
TalC & 0,698 & $-0,185$ \\
DVF & $-1,29$ & $-0,066$ \\
NFV & 0,860 & 0,295 \\
CFL & $-0,088$ & 0,908 \\
DPP & 0,942 & $-0,337$ \\
IAF & $-0,453$ & $-0,312$ \\
\hline
\end{tabular}

Can 1: primeira variável canônica; Can2: segunda variável canônica TaPF: taxa de aparecimento de folhas; TalF: taxa de alongamento de folhas; a taxa de TalC: taxa alongamento de colmos; Filo: filocrono: DVF: duração de vida das folhas; NFV: numero de folhas verdes; CFL: comprimento de lamina foliar; DPP: densidade populacional de perfilhos; IAF: índice de área foliar.

A primeira variável canônica explica $95 \%$ da variação no fluxo de tecidos, além disso, é possível observar uma distribuição diferenciada no fluxo de tecidos entre os pastos estudados (Figura 2).

Figura 2. Distribuição da primeira (eixo $\mathrm{x}$ ) e segunda (eixo y) variável canônica dos pastos Brachiaria brizantha (ecótipo B4 [‡], BRS Paiaguás [ø] e Xaraés [0]).

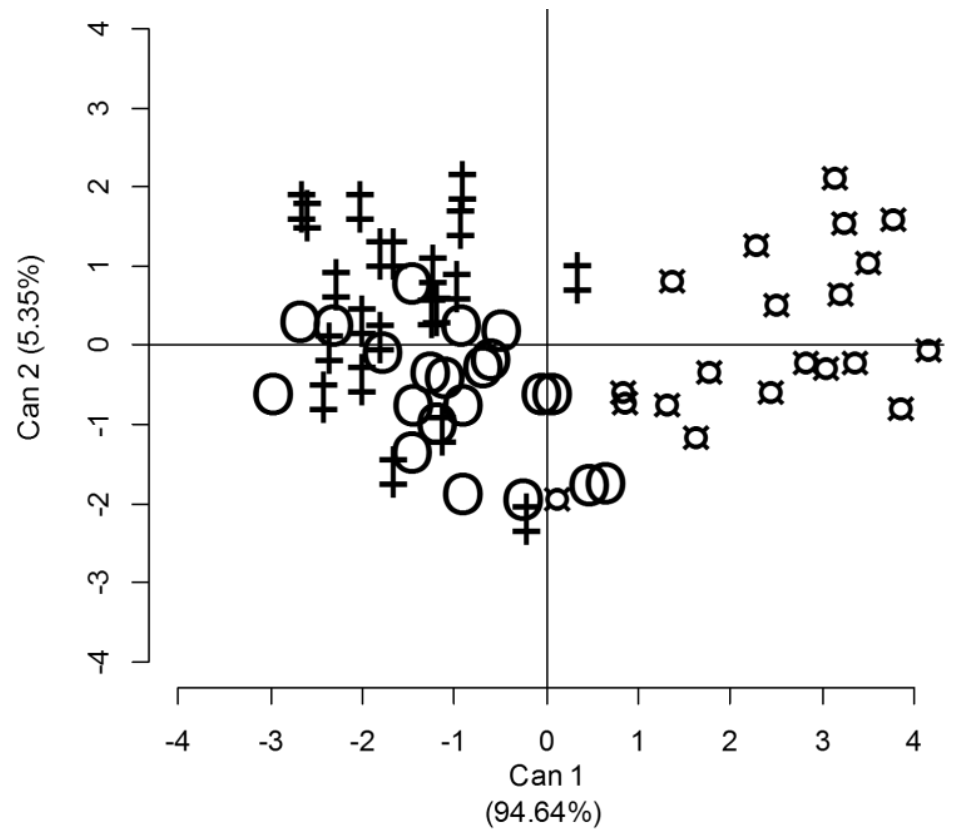

Os pastos do ecótipo B4 apresentam pontos predominante distribuídos na Can1 positiva, enquanto a BRS Paiaguás apresenta pontos equidistribuídos na Can1 positiva e negativa, a cv. Xaraés apresenta pontos predominantes distribuídos na Can1 negativa. Assim, é possível inferir que o ecótipo B4 destaca-se por altos Filo, a cv. Xaraés apresenta maior associação com DVF e para a BRS Paiaguás é possível observar um equilíbrio entre Filo e a DVF.

De acordo com Rodrigues et al. (2012), a cv. Xaraés pertence ao grupo funcional A, sendo o grupo onde as gramíneas apresentam os maiores índices de produtividade, porém sendo as mais propensas a estacionalidade na produção de forragem, pois quanto mais produtiva for à gramínea, maior será a taxa de aparecimento de 
folhas, impactando em menor duração da vida da folha.

Por outro lado, o manejo baseado em dias fixos (25 águas e 35 secas) parece não prejudicar o potencial produtivo desse pasto, segundo Gastal e Lemaire (2015), se o período de descanso permanecer menor que a média de vida útil da espécie de gramínea consideradas, então a eficiência da utilização será otimizada, além do controlar o acúmulo de componentes menos desejáveis, como o colmo.

A BRS Paiaguás apresenta maior plasticidade fenotípica, de acordo com Euclides et al. (2015) está forrageira comparada com a BRS Piatã, apresentou menor redução no acúmulo de forragem, indicando que mesmo passando por estresse hídrico conseguiu manter bons índices de produtividade, indicando que a DVF e Filo tenderam a um comportamento constante ao longo das estações do ano.

Diante disso, em manejos baseados em lotação intermitente recomenda-se que para a diversificação de espécies em ambientes pastoris, a cultivar Xaraés seja utilizada como principal recurso forrageiro no período das águas e a BRS Paiaguás seja utilizada de forma estratégica no período seco.

\section{Conclusão}

A plasticidade fenotípica dos pastos $B$. brizantha pode ser elucidados pela duração de vida de folha e filocrono.

\section{Agradecimentos}

Agradecemos ao Instituto Federal Goiano-Campus Rio Verde e Embrapa-Gado de Corte pelo apoio a este estudo e a FAPEG por conceder a bolsa de estudos.

\section{Referências}

BARBOSA, R. A.; NASCIMENTO JÚNIOR, D. D.; VILELA, H. H., SILVA, S. C. D.; EUCLIDES, V. P. B.; SBRISSIA, A. F.; SOUSA, B. M. D. L. Morphogenic and structural characteristics of guinea grass pastures submitted to three frequencies and two defoliation severities. Revista Brasileira de Zootecnia, v.40, n.5, p. 947-954, 2011.

http://dx.doi.org/10.1590/S1516-

$\underline{35982011000500002}$.

CHAPMAN, D. F.; LEMAIRE, G. Morphogenetic and structural determinants of plant regrowth after defoliation. In: BAKER, M. J. (Ed.).
Grasslands for our world. Wellington: SIR Publishing, 1993. p. 55-64.

DIFANTE, G. D. S.; NASCIMENTO JÚNIOR, D. D.; SILVA, S. C. D.; EUCLIDES, V. P. B.; MONTAGNER, D. B.; SILVEIRA, M. C. T. D.; PENA, K. D. S. Morphogenetic and structural characteristics of marandu palisadegrass subjected to combinations of cutting heights and cutting intervals. Revista Brasileira de Zootecnia, v.40, n.5, p. 955-963, 2011.

https://doi.org/10.1590/S1516$\underline{35982011000500003}$

EUCLIDES, V. P. B.; MACEDO, M. C. M.; VALLE, C. B.; BARBOSA, R. A.; GONÇALVES, W. V. Produção de forragem e características da estrutura do dossel de cultivares de Brachiaria brizantha sob pastejo. Pesquisa Agropecuária Brasileira, v.43, n.12, p. 1805-1812, 2008.

http://dx.doi.org/10.1590/S0100$\underline{204 X 2008001200023}$.

GASTAL, F; LEMAIRE, G. Defoliation, shoot plasticity, sward structure and herbage utilization in pasture: review of the underlying ecophysiological processes. Agriculture, v.5, n.4, p. 1146-1171, 2015.

http://dx.doi.org/10.3390/agriculture5041146.

HODGSON, J. The frequency of defoliation of individual tillers in a set stocked sward. Journal of the British Grassland Society, v.21, p.258-263, 1966. https://doi.org/10.1111/j.13652494.1966.tb00483.x

LARA, M. A. S.; PEDREIRA, C. G. S. Respostas morfogênicas e estruturais de dosséis de espécies de Braquiária à intensidade de desfolhação. Pesquisa Agropecuária Brasileira, v.46, n.7, p. 760-767, 2011. http://dx.doi.org/10.1590/S0100204X2011000700012.

LEMAIRE, G.; CHAPMAN, D. Tissue flows in grazed plant communities. In: HODGSON, J.; ILLIUS, A.W. (Ed.). The ecology and management of grazing systems. Wallingford: CAB International, 1996. p. 3-36.

LEMAIRE, G.; DA SILVA, S. C.; AGNUSDEI, M.; WADE, M.; HODGSON, J. Interactions between leaf lifespan and defoliation frequency in temperate and tropical pastures: a review. Grass and Forage Science, v.64, n.4, p. 341-353, 2009. 
http://dx.doi.org/10.1111/j.1365-

2494.2009.00707.x.

MAZZANTI, A.; LEMAIRE, G. Effect of nitrogen fertilization on herbage production of tall fescue swards continuously grazed by sheep. 2 . Consumption and efficiency of herbage utilization. Grass and forage Science, v.49, n.3, p.352-359, 1994. https://doi.org/10.1111/j.13652494.1994.tb02010.x

RODRIGUES, C. S.; NASCIMENTO JÚNIOR, D.; DETMANN, E.; SILVA, S. C.; SOUSA, B. M. D. L.; SILVEIRA, M. C. T. D. Functional clusters of tropical forage grasses. Revista Brasileira de Zootecnia, v.41, n.6, p. 1385-1393, 2012. http://dx.doi.org/10.1590/S1516-

$\underline{35982012000600010}$ 